\title{
Design and Development of a New Cost-Effective Internet of Things Sensor Platform for Air Quality Measurements
}

\author{
C. Spandonidis ${ }^{1, *}$, S. Tsantilas ${ }^{1}$, F. Giannopoulos ${ }^{1}$, C. Giordamlis ${ }^{1}$, I. Zyrichidou ${ }^{2}$ and P. Syropoulou ${ }^{2}$ \\ ${ }^{1}$ Prisma Electronics SA, Leof. Dimokratias 85, 681 00, Alexandroupoli \\ ${ }^{2}$ Draxis Environmental SA, 54-56 Themistokli Sofouli st 54655, Thessaloniki, Greece
}

Received 16 September 2020; Accepted 16 December 2020

\begin{abstract}
In the present paper, a new, low cost, compact and modular Internet of Things (IoT) platform for air quality monitoring in urban areas is presented. This platform comprises dedicated low cost, low power, hardware and the associated embedded software that enables measurement of particles (PM2.5 and PM10), NO, CO, CO2 and $\mathrm{O} 3$ concentration in the air, along with relative temperature and humidity. This integrated platform acts as part of a greater air pollution data collecting wireless network that is able to monitor the air quality in various regions and neighborhoods of an urban area, by providing sensors measurements at a high rate that reaches up to one sample per second. It is therefore suitable for Big Data analysis applications such as air quality forecasts, weather forecasts and traffic prediction. The first real world test for the newly developed platform took place in Thessaloniki, Greece, where multiple devices were installed in various buildings in the city. Preliminary results from the pilot testing period are provided with focus on COVID-19 impact on air quality.
\end{abstract}

Keywords: Distributed Sensor System, Environmental Monitoring, Internet of Things (IoT), Smart Cities

\section{Introduction}

Poor air quality remains a major environmental concern in many urban agglomerations worldwide. However, quantitative measurements of pollutant concentrations are usually only provided at a few locations. While central environmental monitoring stations, often governmentally operated, may provide accurate information regarding the air quality in a region, as a norm, they are large monitoring stations of high complexity and cost (both for purchase and maintenance). Based on the great advancement of sensor technology and Internet of Things (IoT) applications, a lot of low-cost devices have been introduced in the last decade, enabling a great shift in air quality monitoring approaches towards data collection through IoT-enabled sensor networks [1]. IoT-enabled environmental monitoring sensor networks are an emerging technology that promises better representation of the microclimate of an urban area or certain regions within it, improving our knowledge of emissions and identifying their source, increasing public awareness and lowering harmful exposure to pollutants. Complementary to measurements from central air quality monitoring networks, satellite monitoring and modelling simulations (e.g. weather, air pollution propagation), IoT environmental monitoring platforms can provide accurate and real-time information about the levels of air pollution to scientists and public authorities, for policy making purposes.

While the majority of environmental sensor networkrelated projects is driven by the academia (i.e. government funding), there are also commercial and/or crowd-funded projects, that have been introduced to the public. The most

*E-mail address: c.spandonidis@prismael.com

ISSN: 1791-2377 @ 2020 School of Science, IHU. All rights reserved. doi:10.25103/jestr.136.12 profound of the projects that have been presented are the US EPA funded CAIRSENSE project, that focused on the performance evaluation of different sensors [2], the large scaled, multinational Citi-Sense project, that focused on ambient air quality, indoor environment at schools, and the quality of urban spaces [3] and the Village-Green project, that mainly focused on the power consumption of the wireless monitoring platform [4]. Other projects that have been widely used are the commercially funded AirVisual and Airpurple projects. Both projects are based on relatively low-cost platforms, monitoring the contamination by PM of different sizes and carbon dioxide (AirVisual). In total, during the course of these two projects, more than 10.000 monitoring devices have already been installed and provide data as a service upon request.

McKercher et al. [5] presented a state-of-the-art review of small, portable platforms that measure ambient gaseous outdoor pollutants. Their aim was to address broad trends during the past 5-10 years. In that work, the authors categorized the main environmental monitoring projects according to their sensor capabilities, battery life storage and approximate cost. Focusing mainly on portable platforms, the work gives a good overview of both trends and drawbacks of low cost - large scale projects. Going one step further, Morawska et al. [6] tried to provide some answers to two distinct questions: (1) whether these technologies are fit for the various purposes envisaged and (2) how far have these technologies and their applications progressed to provide answers and solutions. Based on literature review of both peer-reviewed papers and "grey literature", the authors provide a concise overview of the current state of development of low-cost sensing technologies for air quality monitoring and exposure assessment. The most profound environmental monitoring platforms are being categorized based on cost, mobility, sensor technology, wearability, data 
communication protocol, cloud services, processing and dissemination. The authors agree with Snyder et al. [7] in that, while the application of low-cost devices has already changed the paradigm of air pollution monitoring, most of the existing platforms currently fulfil only the first two of the following four tasks: (1) supplementing routine ambient air monitoring networks, (2) expanding communication with communities, (3) enhancing source compliance monitoring and (4) monitoring of personal exposures.

In order to address the above challenges, this work presents a low-cost, adjustable, wireless sensor platform for air pollution monitoring in urban areas. The platform is capable of real-time measuring of the concentration of Nitric Oxide (NO), Nitrogen Dioxide $\left(\mathrm{NO}_{2}\right)$, Ozone $\left(\mathrm{O}_{3}\right)$, Carbon Monoxide (CO), as well as concentration of $\mathrm{PM}_{2.5}$ and $\mathrm{PM}_{10}$ sized particles in the air [8]-[11]. Throughout this paper, it is shown that the platform presented in this work can be adjusted to connect to up to four different sensors, according to the requirements of each application. The platform operates as part of a grid of distributed measuring stations, collecting data for air pollution monitoring applications. This study is implemented as part of the ongoing funded project "SympniaAir quality monitoring and forecasting using satellite and low-cost sensors deriving data", during the course of which a detailed local air quality map is being developed [12]. This work focuses on the smart collector part (hardware and embedded software) of the project, while Software Application will be part of our next work.

The rest of the paper is structured as follows: In Section 2 , we briefly present the basic architecture of the Sympnia IoT Platform. We then introduce and describe both the hardware and the embedded software developed for the Sympnia Smart Collector, which constitutes the basic module of the Sympnia IoT Platform. In Section 3, the laboratory testing methodology of the IoT platform is presented. Test results and general outcome of the tests performed are also discussed. In Section Error! Reference source not found., we present preliminary results from the test pilot phase. Finally, in Section 5, we discuss the key results of the study.

\section{System Description}

\subsection{System Architecture}

The development of the Sympnia IoT Platform was based on Prisma Electronics' PrismaSense ${ }^{\mathrm{TM}}$ system [13], which was redesigned to measure the concentration of 6 atmospheric pollutants: $\mathrm{PM}_{10}, \mathrm{PM}_{2.5}, \mathrm{NO}_{2}, \mathrm{NO}, \mathrm{O}_{3}$ and $\mathrm{CO}$. Data from lowcost sensors are collected via a dedicated device that runs specially developed embedded software for sensor data collection and wireless transmission. This device is named "the Smart Collector". An Application Programming Interface (API) was developed on the air quality platform for receiving datasets from the Smart Collectors, storing them in a database and sending them to a web and mobile application. The Sympnia software platform is built upon an existing commercial system developed by DRAXIS, named Envi4All [14], that provides services of air quality monitoring and forecasting.

Except from data from official ground-based air quality monitoring stations, the Sympnia software platform uses satellite data from the Copernicus Atmosphere Monitoring Service (CAMS), and measurements from low-cost sensors that will be placed in the greater area of Thessaloniki during the pilot implementation of the Sympnia project.

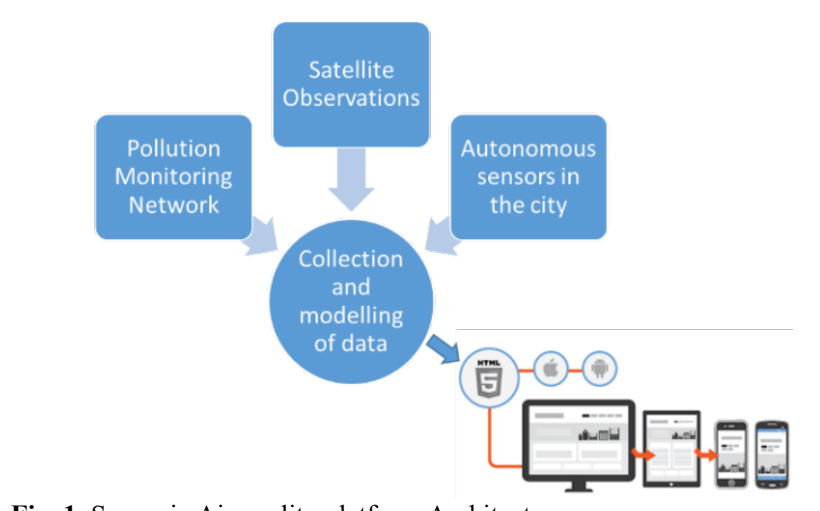

Fig. 1 Sympnia Air quality platform Architecture

The collected information is displayed in near real time and in high spatial and temporal resolution. Simplified air quality indices will be provided to citizens along with personalized recommendations on how they can protect their health from air pollution. It is expected that the collected data will also enable the identification of air pollution trends that may lead to policy changes and, in longer term, to behavioral change.

\subsection{Smart Collector Design}

The Smart Collector consists of a microcontroller and the appropriate interfaces to connect to the sensors. Furthermore, it performs data pre-processing and calculation of several parameters. The sampling rate, as well as the rate of the parameters calculations, can be set from 1 second up to 30 minutes. During the course of the Sympnia project, two versions of the Smart Collector were developed. The main difference between the two versions is the microcontroller that was chosen for data acquisition and wireless communication with the remote server.

The main technical specifications of the first version of the Sympnia Smart Collector are summarized in Table 1.

Table 1 Technical specifications of the First Version

\begin{tabular}{c|l}
\hline \multicolumn{2}{c}{ Technical Specifications } \\
\hline Category & \multicolumn{1}{c}{ Type } \\
\hline Processor & Xtensa ${ }^{\circledR} 32-\mathrm{bit}$ \\
Memory (RAM) & L106/80MHz \\
Primary Wireless & Wi-Fi $802.11 \mathrm{~b} / \mathrm{g} / \mathrm{n}$ \\
Communication & $3 \times$ UART, $1 \times \mathrm{I}^{2} \mathrm{C}$ \\
Sensor communication & $5 \mathrm{~V} \mathrm{DC}($ micro- \\
Power & USB)/battery \\
Max Current & $1.5 \mathrm{~A}$ \\
\hline
\end{tabular}

The main processing module found on the first version of the Sympnia Smart Collector board is an ESP8266 [15], manufactured by Espessif. The module is an ultra-low power, mixed signal microcontroller with a single core 32-bit RISC CPU running at $80 \mathrm{MHz}$, incorporating $512 \mathrm{~KB}$ of RAM.

Following the initial test period (pilot testing) new requirements arose and the collector was re-designed in order to incorporate the ESP32 microcontroller [16], also manufactured by Espressif. The module is an ultra-low power, mixed signal microcontroller with a dual core 32-bit RISC $\mathrm{CPU}$ running at $160 \mathrm{Mhz}$ to $240 \mathrm{Mhz}$ and incorporating a $512 \mathrm{~KB}$ RAM memory. The modification mainly focused on providing the platform with advanced interface capabilities as well as the ability to support connectivity via both Wi-Fi and 
BLE. The microcontroller's main features are presented in Table 2.Error! Reference source not found.

Table 2 Technical specifications of the second Version

\begin{tabular}{c|l}
\hline \multicolumn{2}{c}{ Technical Specifications } \\
\hline Category & \multicolumn{1}{c}{ Type } \\
\hline Processor & Dual Core Xtensa ${ }^{\circledR}$ 32- \\
& bit LX6/ 160Mhz to \\
Memory (RAM) & $240 \mathrm{Mhz}$ \\
Primary Wireless & WiFi $802.11 \mathrm{bB} / \mathrm{g} / \mathrm{n}$ \\
Communication & \\
Secondary Wireless & BLE \\
Communication & $3 x$ UART, $1 \times \mathrm{I}^{2} \mathrm{C}$ \\
Sensor communication & $5 \mathrm{~V} \mathrm{DC} \mathrm{(micro-}$ \\
Power & USB)/battery \\
Max Current & $1.5 \mathrm{~A}$ \\
\hline
\end{tabular}

Both Smart Collector versions can be connected to a computer via USB and are easily programmable through an inhouse development environment (IDF) or through third party IDEs. They incorporate advanced calibration circuitry for dynamic removal of imperfections inserted from external conditions.

The Sympnia Smart Collector is compatible with all $5 \mathrm{~V}$ and $3.3 \mathrm{~V}$ sensors that use UART, I2C, SPI and GPIO protocols. For the purpose of the "Sympnia" project, five (5) different sensor platforms were used, as shown in Table 3.

Table 3. Technical specifications of $\tau$ the sensors

\begin{tabular}{|c|c|}
\hline \multicolumn{2}{|c|}{ Sensors' Specifications } \\
\hline Type & Measurement/Unit \\
\hline $\begin{array}{l}\text { Honeywell HPM } \\
32322550\end{array}$ & $\mathrm{PM}_{2.5}$ and $\mathrm{PM}_{10}\left(\mu \mathrm{g} / \mathrm{m}^{3}\right)$ \\
\hline Euro Gas 4-NO-250 & $\mathrm{NO}(\mathrm{ppm})$ \\
\hline $\begin{array}{l}\text { SPEC DGS-CO 968- } \\
042\end{array}$ & $\begin{array}{l}\mathrm{CO}(\mathrm{ppm}) \text {, temperature }\left({ }^{\circ} \mathrm{C}\right) \text {, } \\
\text { relative humidity }\end{array}$ \\
\hline $\begin{array}{l}\text { SPEC DGS-NO2 968- } \\
043\end{array}$ & $\begin{array}{l}\mathrm{CO}_{2}(\mathrm{ppm}) \text {, temperature }\left({ }^{\circ} \mathrm{C}\right) \text {, } \\
\text { relative humidity }\end{array}$ \\
\hline $\begin{array}{l}\text { SPEC DGS-O3 968- } \\
042\end{array}$ & $\begin{array}{l}\mathrm{O}_{3}(\mathrm{ppm}) \text {, temperature }\left({ }^{\circ} \mathrm{C}\right) \text {, } \\
\text { relative humidity }\end{array}$ \\
\hline
\end{tabular}

The sensor manufacturers are limited and one of the most important factors for selecting a low-cost, reliable sensor is the calibration of the sensors [5]. Therefore, the selection among the low-cost air quality sensors for the Sympnia project was based on three criteria: (a) calibration sheets provision from the manufacturer, (b) provision of detailed description of acquisition and transmission procedures, (c) impact of sensors on literature. The Sympnia platform provides normalization of the measured data with respect to the temperature and humidity of the device's surrounding environment.

The Sympnia Smart Collector can be adjusted to operate up to 4 sensors at a time, it can operate for up to five days on an $18650 \mathrm{Li}$-ion battery on a single charge (full operation) and can easily be charged via micro-USB. Fig. 1 provides a detailed depiction of the first version of the Sympnia Smart Collector from each side of the PCB, while Fig. 2 depicts both sides of the Sympnia Smart Collector's second version. In both figures indicative sensors have been mounted on the board for illustrative reasons.

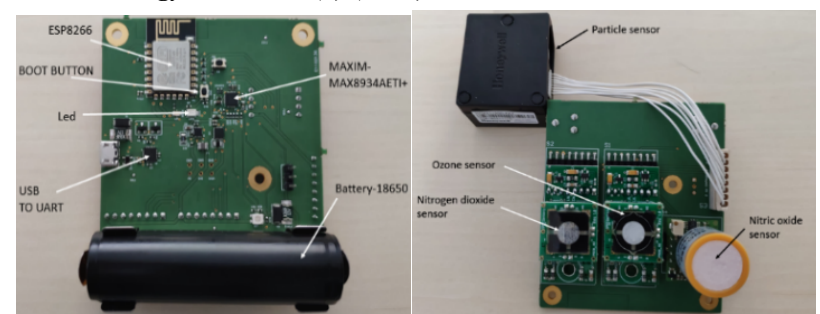

Fig. 1. The Sympnia Smart Collector version 1.

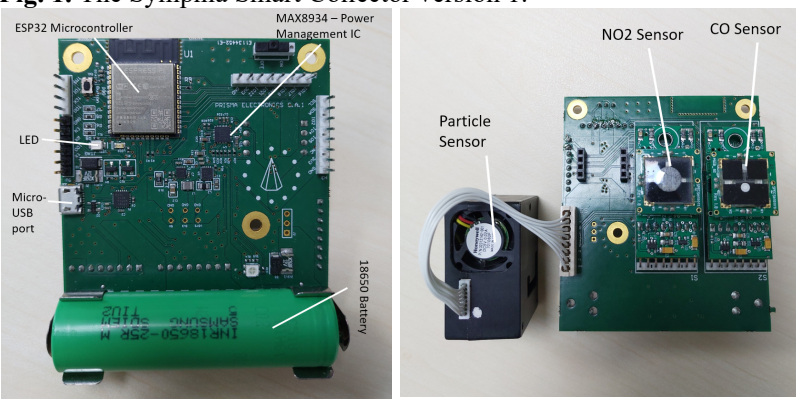

Fig. 2. The Sympnia Smart Collector version 2.

For the housing of the Smart Collector, a 3D printed case, shown in Fig. 3 was developed. The housing has been designed so as to enable proper airflow and protection of the sensors as well as to enable safe and secure operation of the platform in open space. The Smart Collector's PCB dimensions are $8 \times 8 \mathrm{~cm}$ making it suitable for low profile, incity applications that require installation on balconies, train stations, bus stations, airports, etc.

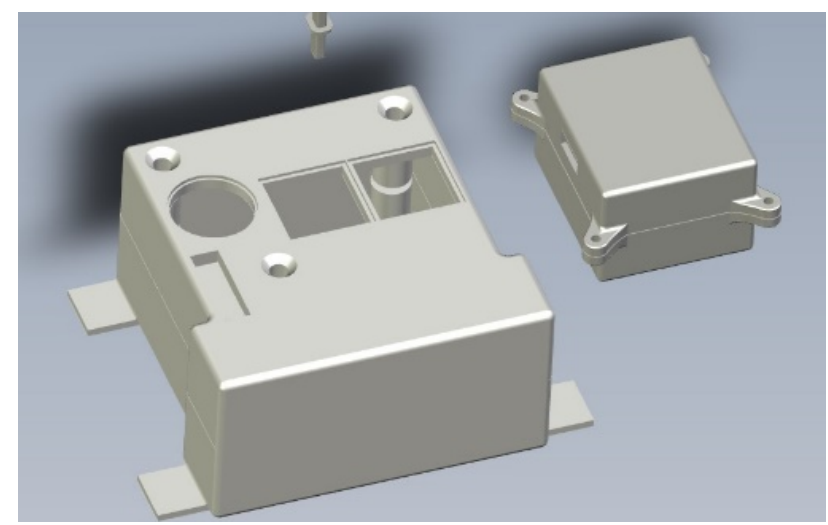

Fig. 3. Sympnia IoT platform's housing.

\subsection{Embedded Software Design}

The embedded software for the Sympnia IoT Platform has been developed around four main groups of functions: (a) initialization of the platform, (b) measurement activities and visual indication, (c) preparation of data for transmission, (d) transmission of the data. Each one of the groups provides distinct functionalities to the system, as described below.

Initialization group. Within this group of functions, the Smart Collector initialization and initial configuration takes place. The functions are called once on startup or after a reset occurs. The device initialization includes configuration of the device's LEDs, the sensors selected, as well as the USB debugging and Wi-Fi modules.

Mainloop group. Within this group of functions, the platform checks every $1 \mathrm{~ms}$ weather the device is connected to a Wi-Fi network and whether the time is set. Furthermore, the device performs a check every minute to determine its connection status to the remote server. The measurements from the 
sensors are transmitted every minute for a period of 5 minutes and then every hour. The device prints status messages in a serial communication port and changes the LED displays to manifest the state of the device accordingly. The core of the aforementioned functionality is depicted in Fig. 4.

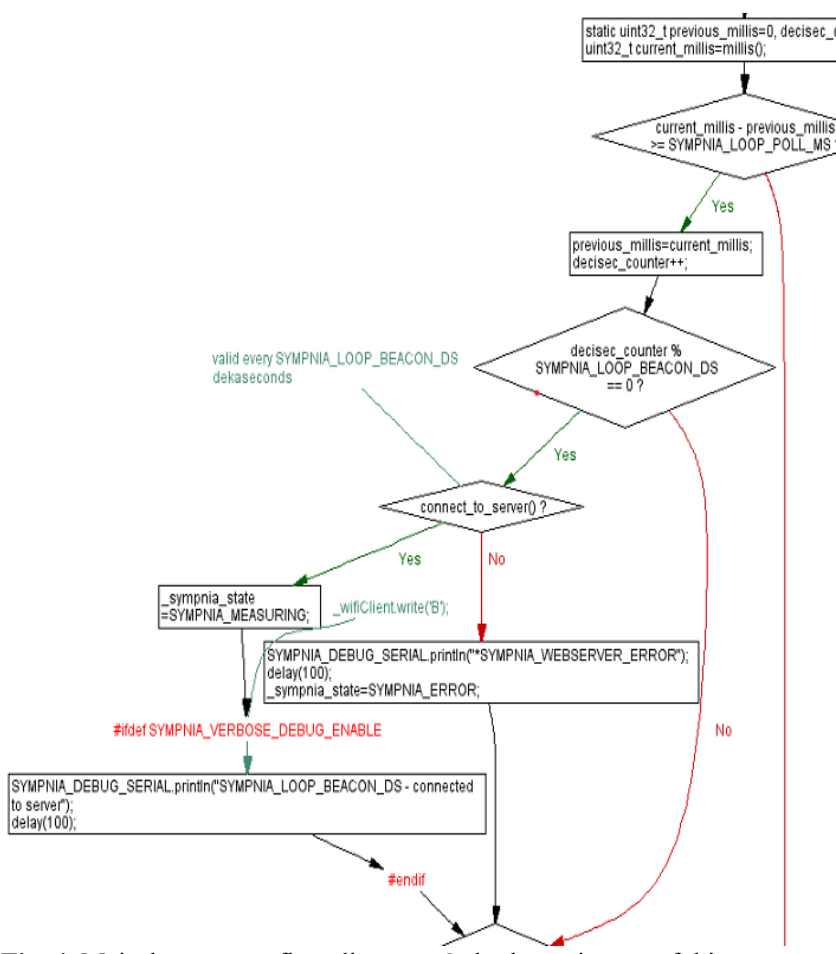

Fig. 4. Main-loop group flow diagram. Only the main part of this group is depicted.

A different library for each sensor has been written in order to secure proper communication with the different protocols used and to enable specialized data acquisition and management for each one of the sensors.

Post function: The Smart Collector initially sets up a wireless secure network in order to be configured, it then connects to a wireless network that is set up either inside a building or in an open area, it transmits the pre-processed data to a local router and, from there, to a central server where an existing air quality platform is operating. Data are being transmitted in real time and on an hourly base. A custom-made communication protocol has been adopted in order to transmit both measurement values and corresponding meta-data (e.g. time, location, ID, log data) through a JSON file. The Post function is used to send all measurements inside an HTTP POST method in a JSON packet. The JSON body consists of an access key, a metric, a measurements array and a timestamp. Each measurement cell includes a metric (e.g. $\mathrm{NO}_{2}$ ), a spec (for metrics TEMP and HUM only, referring to temperature and humidity measurements respectively, the spec field indicates whether the measurement is coming from the $\mathrm{NO}_{2}$, $\mathrm{CO}$ or $\mathrm{O}_{3}$ sensor) and a value. The function returns the code of the http response. Fig. 5 presents a flow chart of the Post function's main functionality after data acquisition.

Send function. This function sends the measurements acquired from the sensors via a JSON packet to the defined server. If the collected data are successfully sent, the function returns a True value; otherwise, it returns a False value. In case no connection is achieved, the system restarts. The Send function's flow diagram is depicted in Fig. 6.

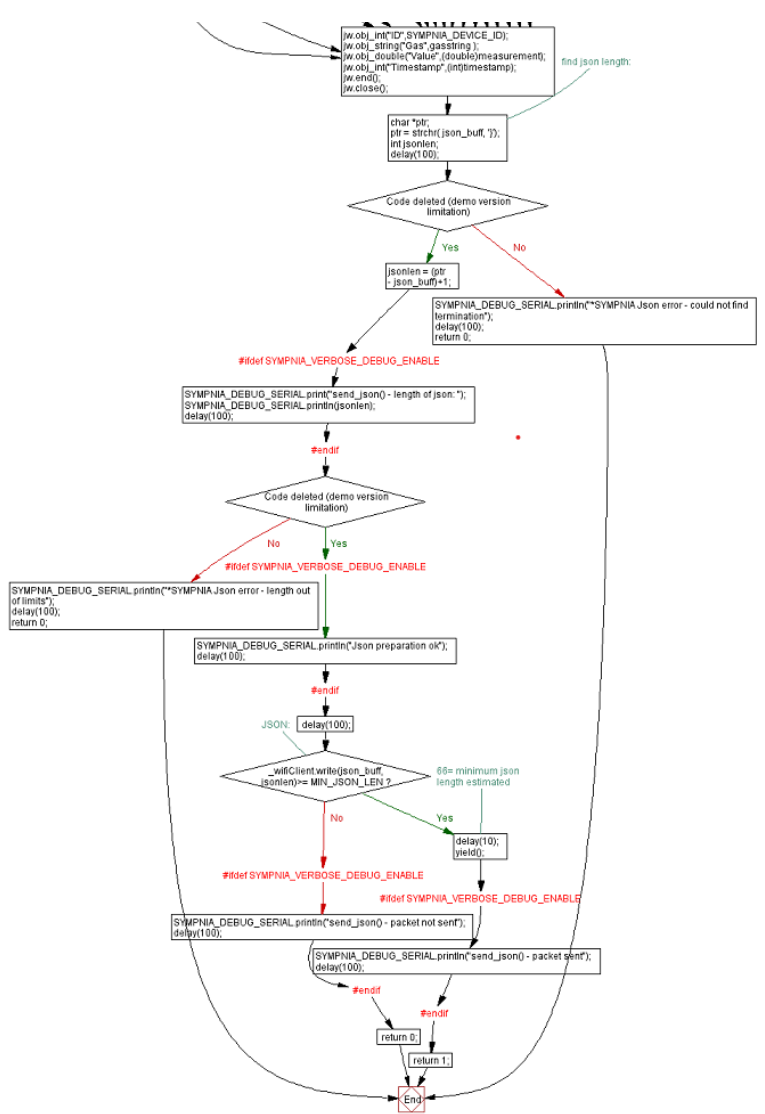

Fig. 5. Post function flow diagram. Only the part after measurement collection is depicted.

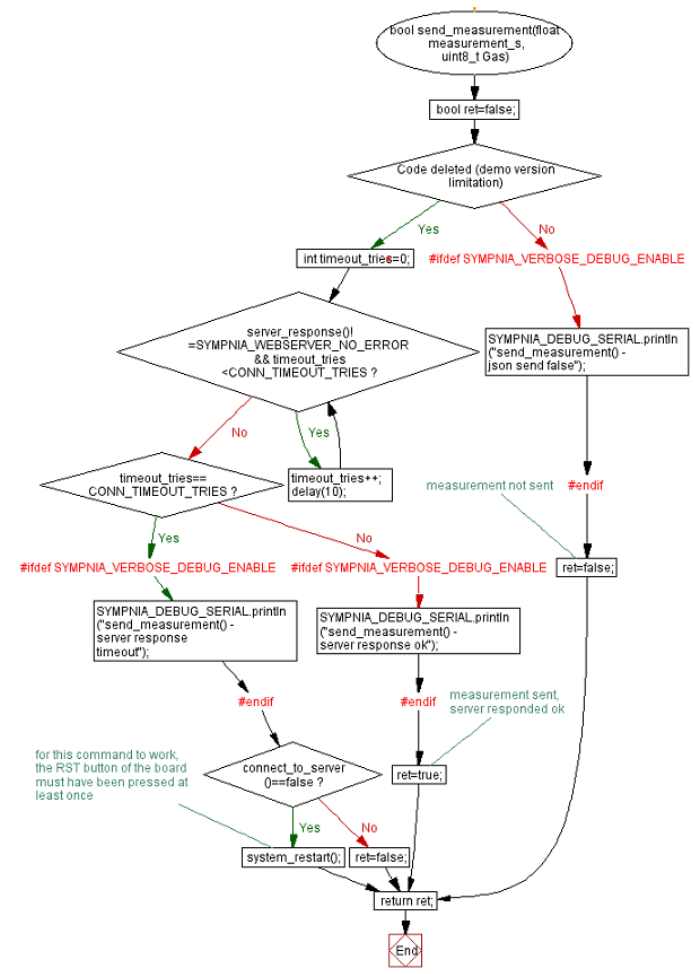

Fig. 6. Send function flow diagram.

\subsection{Software Application}

The Sympnia software platform is an easy-to-use platform that provides targeted information to citizens about the current and forecast levels of air pollution (Fig. 7). 


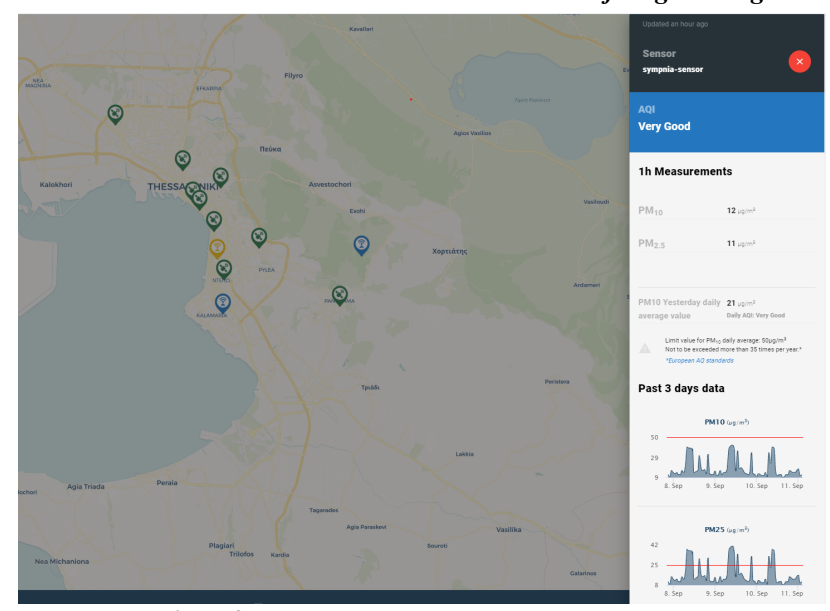

Fig. 7. Sympnia Software API

The API integrates air quality measurements from more than 10.000 official air quality monitoring stations and lowcost sensing devices from all around the world, that offer their measurements as open data. The platform displays the information in the form of an Air Quality Index, so that it is easily understandable by citizens, accompanied with a colour characterization that is defined by the current air quality levels. In addition, the platform provides statistics on the recent measurements of each station and sensing device, and indication whenever the official limits are breached. Through the API, citizens can register their Sympnia sensing device, visualize its measurements on the map, see statistics, and download the data for further use.

\section{Hardware System Testing}

This section presents a summary of the results of laboratory and in-field evaluation tests performed on the hardware components, prior to their installation in the field, following standard testing approaches [17]. Components selected are indicative of the ones to be installed during the pilot testing. The integrity and robustness of the measurements was assured by performing each series of measurements at least 3 times, according to the standard laboratory test practice. Reported values are averaged and standard error is depicted when applicable. The tests presented in this section were performed initially for the first version of the Smart Collector and were repeated for testing its second version as well. As expected, the two versions behave in a similar manner regarding accuracy, quality and efficiency of data. In the present section, when not specified, the performed tests were executed with both versions of the Smart Collector.

Table 4 summarizes the followed test procedures. Each test is described in detail in the corresponding paragraph. These tests aimed at evaluating the functionality and the characteristics of the Sympnia Smart Collector; therefore, the effects of third party components (e.g. Wi-Fi routers) on the presented results are only reported if any deviation from the rest of the measurements has been identified.

Table 4. Hardware Evaluation procedures

\begin{tabular}{c|l}
\hline Testing & \multicolumn{1}{|c}{ Measurement/Unit } \\
\hline Accuracy & $\begin{array}{l}\text { Comparison between data reported by the } \\
\text { collector and values collected by ground } \\
\text { station. Fixed source. }\end{array}$ \\
Regression & $\begin{array}{l}\text { Same as accuracy but for multiple values. } \\
\text { Fixed source. }\end{array}$
\end{tabular}

\begin{tabular}{|c|c|}
\hline Testing & Measurement/Unit \\
\hline Stability & $\begin{array}{l}\text { Same as accuracy but for longer time. Fixed } \\
\text { source. }\end{array}$ \\
\hline Sensitivity & $\begin{array}{l}\text { Comparison between data reported by the } \\
\text { collector and the mean value reported by } \\
\text { multiple collectors. Changing source output. }\end{array}$ \\
\hline $\begin{array}{l}\text { Data } \\
\text { Integrity }\end{array}$ & $\begin{array}{l}\text { Calculation of data loss packets and time } \\
\text { shift. }\end{array}$ \\
\hline System & $\begin{array}{l}\text { Evaluation of operational and performance } \\
\text { specifications with installation architecture. }\end{array}$ \\
\hline $\begin{array}{l}\text { User } \\
\text { acceptance }\end{array}$ & $\begin{array}{l}\text { Evaluation of Human Experience and } \\
\text { Human-Machine Interface. }\end{array}$ \\
\hline
\end{tabular}

\subsection{Accuracy Testing}

This test involves comparison of the collected signals with those reported by a reference point. At this stage, data from Sympnia Smart Collectors were compared to data obtained by ground stations. Specifically, different collectors were mounted within close proximity to an environmental Ground Station, in the center of Athens, located in the Omonoia square. Due to the measurements that can be obtained by the Ground Station, only $\mathrm{PM}_{10}$ and $\mathrm{NO}_{2}$ sensors were evaluated. The accuracy tests focused on evaluation of deviation from the Ground Station reported values. The $\mathrm{NO}_{2}$ and $\mathrm{PM}_{10}$ measurements from the ground station were collected by the ENVI4All ${ }^{\mathrm{TM}}$ software and are graphically depicted in Fig. 8. In order to calculate the accuracy of the sensors, the time period during which each reported value was stable and the corresponding measurement were selected for comparison.

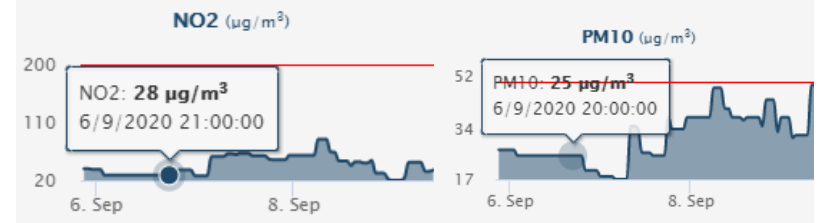

Fig. 8. Three day measurements reported by the Ground Station. Specific values used for accuracy testing are also marked.

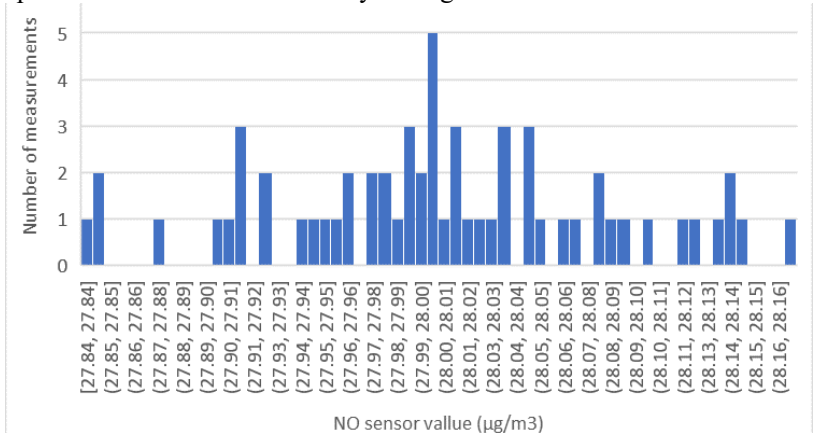
NO sensor vallue $(\mu \mathrm{g} / \mathrm{m} 3)$

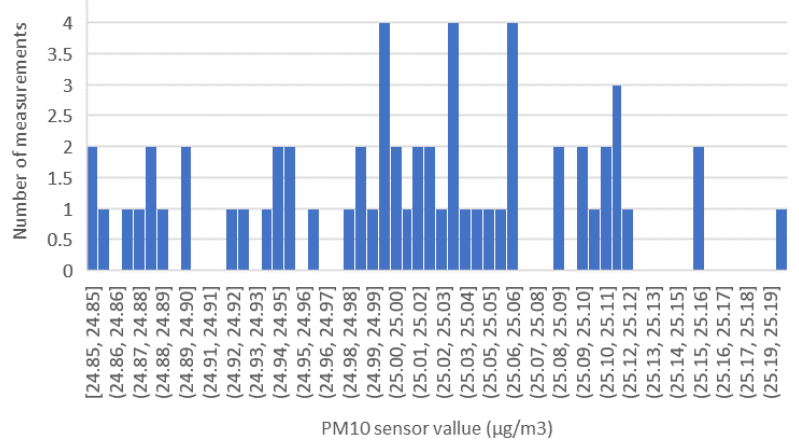

Fig. 9. Distribution of measurements taken from Sympnia Smart Collectors within the reference period for accuracy tests: (up) NO sensor, (down) $\mathrm{PM}_{10}$ sensor. 
In Fig. 9, the two histograms present the measurements distribution taken from the Sympnia Smart Collectors equipped with $\mathrm{NO}$ (up) and $\mathrm{PM}_{10}$ (down) sensors. For the reference period, the measurements reported from the Sympnia Smart Collectors were captured and in Fig. 10 the distribution of these values for the relevant Ground Station sensors is provided. As shown in the figure, the measurements reported by the Sympnia Smart Collectors follow the ones of the Ground Station's reference measurements well.
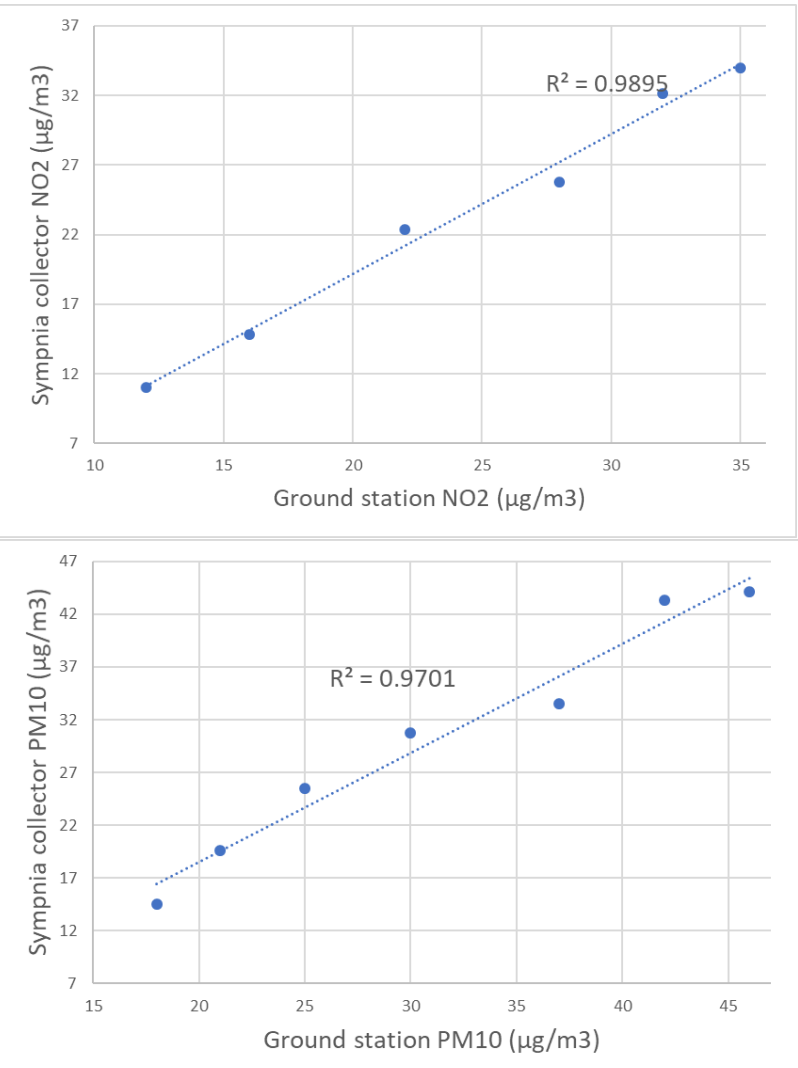

Fig. 10. Linear regression of measurements from Sympnia Smart Collectors and the Ground Station for $\mathrm{NO}_{2}$ (up) and $\mathrm{PM}_{10}$ (down) sensors.

\subsection{Regression Testing}

This test involves comparison between measurements taken from a number of Sympnia Smart Collectors and the Ground Station for different sample periods. These time periods have been selected so that each one of them includes unique, stable values. Measurements were recorded on regular time intervals (e.g. every 1 hour). Linear Regression models were applied in order to estimate any deviation between the two sets of measurements.

Fig. 10 presents the regression testing results for data taken from the two sensors used in the accuracy test, namely $\mathrm{NO}_{2}$ and $\mathrm{PM}_{10}$. In order to quantify this result, the R-squared values were also calculated. In most cases, the R-squared values are very close to unity; that is proof of good measurements linearity.

\subsection{Stability Testing}

The stability testing is similar to the previous one but involves evaluation of deviation from reference values for a longer period. In our case, due to the absence of reference sources, we proceeded as follows: We mounted a large number of Sympnia Smart Collectors inside a Class 10.000, ISO-7 Clean Room for 5 hours, during the night. The decision to perform this kind of test during the night hours was based on both the need for stable values and the availability of the facilities. In order to increase the number of samples taken during the limited period and to maximize the measurements' deviation resolution, the Smart Collectors were configured to sample the sensors at a rate close to their limits.

Fig. 11 presents indicative examples from the outcomes of the testing for a group of $\mathrm{NO}_{2}$ sensors. Due to the absence of reference values, the measurements' mean value was used as a reference value and the deviation from it was calculated. Quality control on data was performed before any mean value calculation, in order to exclude spikes (instant outliers) and/or malfunctioning sensors' measurements from the obtained average values. As shown in Fig. 11, deviation of measurements from the reference value is acceptable for further processing of the data.

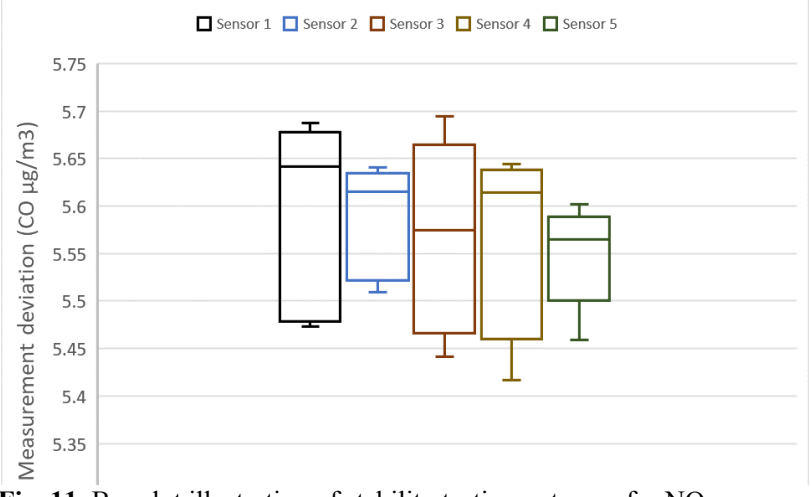

Fig. 11. Boxplot illustration of stability testing outcome for $\mathrm{NO}_{2}$ sensors.

Fig. 12 depicts the outcome of stability testing for all groups of sensors. The vertical axis represents the average, while the size of the bubble depends on the deviation from this mean value within the group. It is shown that "Sympnia" collectors perform very efficiently.

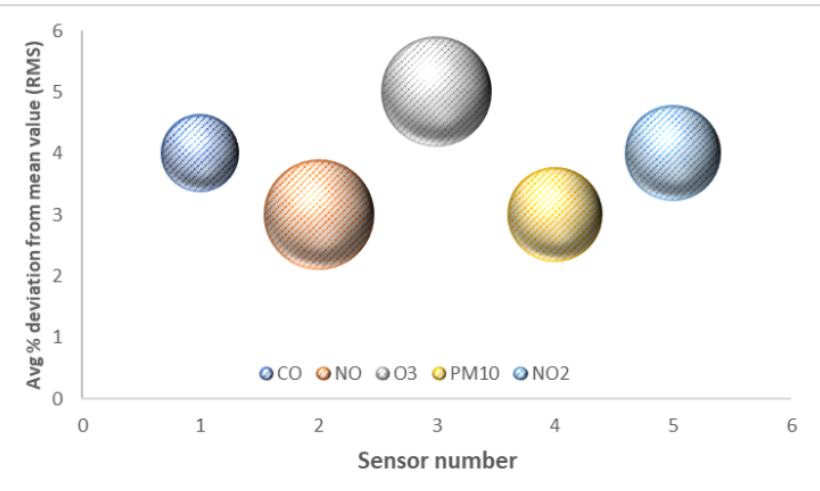

Fig. 12. Normalized to the average values from the $\mathrm{NO}_{2}$ sensors of the three devices (a) and correlation of the sensors' measurements.

\subsection{Sensitivity Testing}

While previous testing involved static signal, in the sense that the excitation seen as the input to the Smart Collectors was fixed for each test, this kind of testing involved signals that change over time. It has to be noted that only steady state signals (fixed value of source output after change) and not transient period (time during the change) signals were evaluated due to laboratory restrictions.

Initially, three different Sympnia Smart Collectors (version 1) with the same sensor configuration were installed in the same location and as close as possible to each other, as shown in Fig. 13. The measured data from each individual 
Smart Collector were captured for 24 hours and the mean value from all devices' measurements were extracted for each time stamp. This test involved comparison of each device's collected data series with the average value of data series from all devices and calculation of the relevant dispersion.

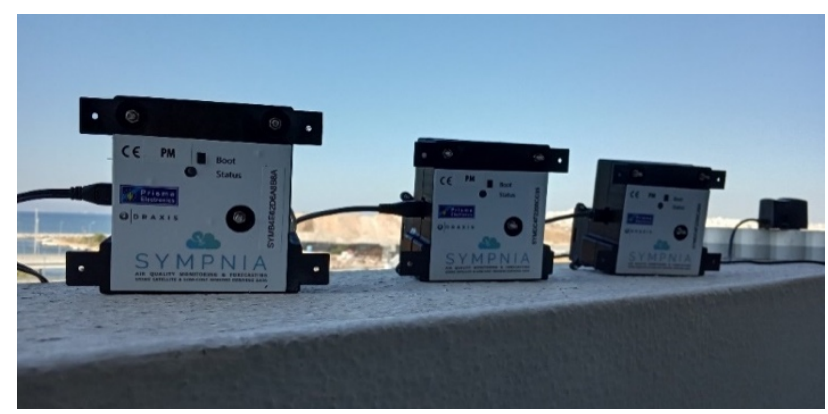

Fig. 13. Three different Sympnia Smart Collectors have been installed in the same location in order to proceed with sensitivity testing.

Fig. 14 depicts the percent distribution of measurements from the mean value for three different devices along with the average value. In order to quantify this result, the values for each sensor compared to the others were plotted and the Rsquared values were calculated in order to represent the proportion of the variance between them. An indicative result for CO measurements can be seen in Fig. 15. In most cases, the R-squared values have been measured very close to unity; that is proof of good linearity and high level of platform sensitivity. Visual inspection of both Fig. 14 and Fig. 15 provides confidence regarding the good sensitivity of the platform. Extended results from this test have been presented in [18].

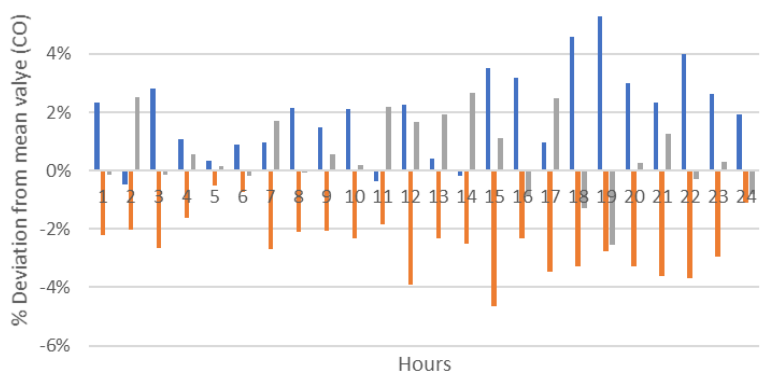

Fig. 14. Percent distribution of $\mathrm{CO}$ measurements from the mean value for three different Sympnia Smart Collector version 1 devices.

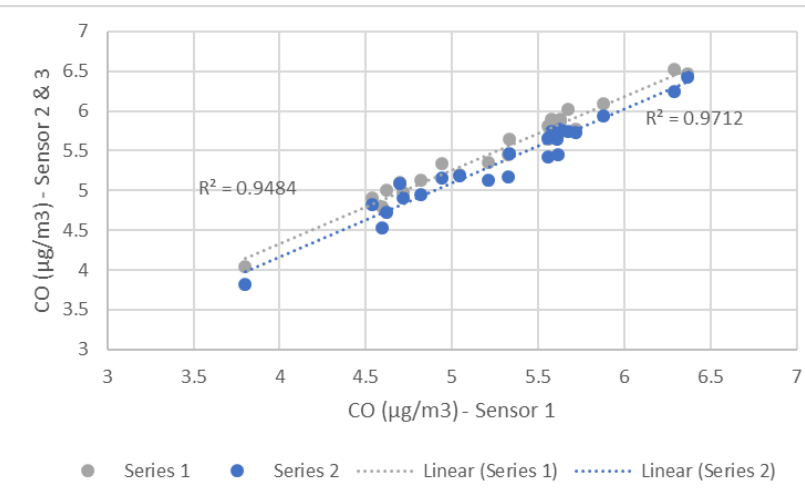

Fig. 15. Correlation of CO sensors' measurements along different pairs of sensors. The corresponding measurements were obtained using Sympnia Smart Collector version 1 devices.

After development of version 2 of the Sympnia Smart Collector the tests were repeated using both versions of the hardware. This time measurement were taken from a larger number of collectors (up to 17), prior to their installation in the field for pilot testing. The percent distribution of $\mathrm{PM}_{10}$ measured values for each one of the sensors is graphically provided in Fig. 16. Fig. 17 summarizes the outcome of an inter-correlation test between several different $\mathrm{PM}_{10}$ sensor pairs. Specifically, the R-squared value from the linear regression is depicted for each one of the pairs. The results demonstrate the good linearity of the sensors in the large scale.

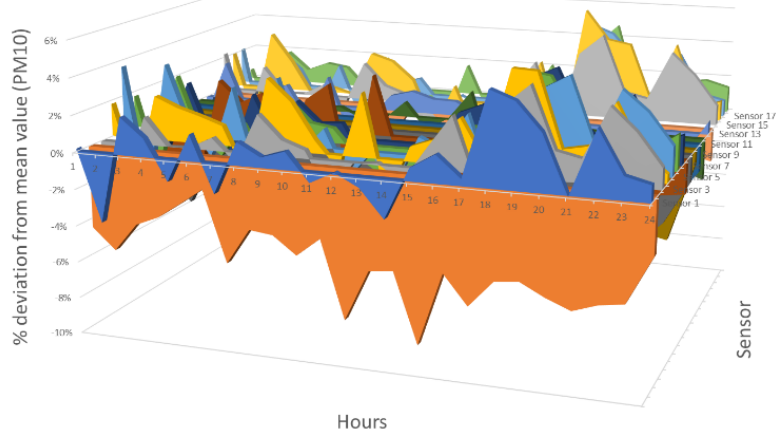

Fig. 16. Percent distribution of $\mathrm{PM}_{10}$ measurements from the mean value for 17 different Sympnia Smart Collector version 2 devices.

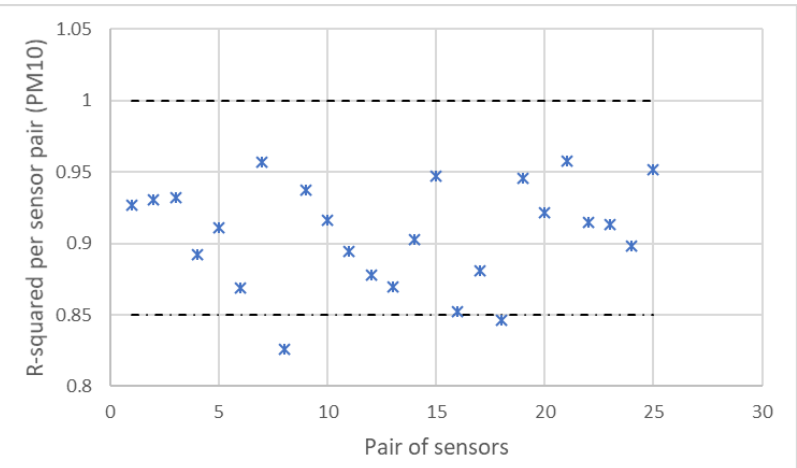

Fig. 17. $\mathrm{R}^{2}$ indicator of $\mathrm{NO}_{2}$ sensors' measurements along different pairs of sensors. The corresponding data were collected by Sympnia Smart Collector version 2 devices.

Fig. 18 collectively illustrates similar results for the different types of sensors tested. It is shown that in the vast majority of the tests the R-squared values were calculated within the range $0.85-1$. In some occasions, $\mathrm{R}$-squared values of less than 0.85 were calculated. In these cases, the sensors were re-calibrated, and the tests were repeated.

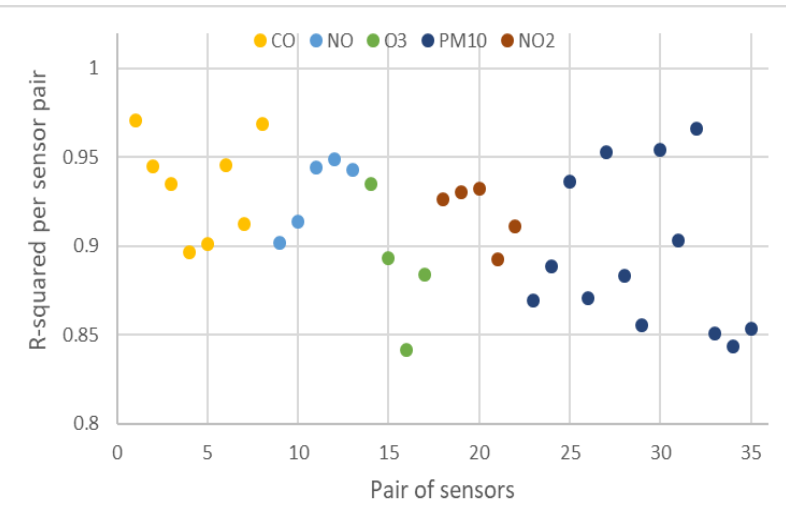

Fig. 18. $\mathrm{R}^{2}$ value of indicative sensor tests using Sympnia Smart Collector version 2 devices. The dots' different colors indicate the different types of sensors used. 


\subsection{System Testing}

This test involved evaluation of the Sympnia Smart Collectors operation according to its specifications. The evaluation procedure included testing of the system under both normal and non-normal conditions, so that the platform's operation and outputs could be tested during its normal operating conditions, as well as in case of malfunction. When needed, simulated signals where used as a system input. A brief description of the testing scenarios and the outcome of each one is provided in Table 5 .

Table 5. IoT platform system tests.

\begin{tabular}{|c|c|}
\hline \multicolumn{2}{|r|}{ Sympnia IoT Platform Test Cases } \\
\hline Test Case & Test Description \\
\hline $\begin{array}{l}\text { Normal } \\
\text { Operation }\end{array}$ & $\begin{array}{l}\text { The device connects to a network, collects } \\
\text { data, sends data, sleeps and repeats. Normal } \\
\text { use of LED indications }\end{array}$ \\
\hline $\begin{array}{l}\text { Initial } \\
\text { connection } \\
\text { to the } \\
\text { internet }\end{array}$ & $\begin{array}{l}\text { The device connects to a network at device } \\
\text { startup }\end{array}$ \\
\hline $\begin{array}{l}\text { Connectio } \\
\mathrm{n} \text { Loss }\end{array}$ & $\begin{array}{l}\text { The device connects to a network at first but } \\
\text { cannot achieve Wi-Fi connectivity at a next } \\
\text { wake-up cycle }\end{array}$ \\
\hline Problemati & Sensor is not operating properly \\
\hline $\begin{array}{l}\text { Time } \\
\text { server fault }\end{array}$ & $\begin{array}{l}\text { After connection to a network, the device } \\
\text { cannot access a time server }\end{array}$ \\
\hline $\begin{array}{l}\text { Server not } \\
\text { available }\end{array}$ & $\begin{array}{l}\text { After connection to a network, the device } \\
\text { cannot access the Sympnia server }\end{array}$ \\
\hline
\end{tabular}

As shown in this table, the platform is able to correctly measure and send data, as well as blink, sleep and wake-up. In addition, auto connect provision fires up properly and behaves as expected upon connection loss, malfunctioning sensor, timeserver fault and Sympnia server unavailability.

\subsection{Data Integrity Testing}

This test involved (a) Calculation of data packages loss and time shift, (b) Collection and transfer of data in periodic intervals between a number of Sympnia Smart Collector devices and a remote server. The evaluation of the results was based on the comparison between the data transmitted from the devices and the ones collected in the server. Three parameters were evaluated in all cases: (a) The number of values collected and stored in a database compared to the number of values that was expected (b) The rate of the reported values compared with the sampling rate and (c) The number of missing values.

Testing proved that all values were successfully transferred to the end destination without loss or duplication and on the correct sampling rate. Deviation from the precise sample timing intervals occurred. This deviation was of the order of one (1) second and it is assumed to happen due to noise in the link budget.

\subsection{User acceptance}

This test involved (a) Evaluation of Graphical Interface Design and Human Experience on initial steps of system setup; (b) Evaluation of Installation procedure and customization effectiveness and c) Evaluation of quality and usefulness of data. Feedback provided by people who performed test procedures was adopted in the latest version and the comments are presented in Table 6.
Table 6 Test results: User Acceptance Test

\begin{tabular}{|c|c|}
\hline Test ID & Comments \\
\hline GUI Design & $\begin{array}{l}\text { Minor Changes related to data } \\
\text { arrangements were adopted in the final } \\
\text { release. }\end{array}$ \\
\hline UX & N/A \\
\hline Installation & $\begin{array}{l}\text { Installation procedure performed several } \\
\text { times by different users. }\end{array}$ \\
\hline HW quality & $\begin{array}{l}\text { Daily tasks based on RTA data performed } \\
\text { with success. }\end{array}$ \\
\hline $\begin{array}{l}\text { Data } \\
\text { usefulness }\end{array}$ & $\begin{array}{l}\text { Defects on malfunctioning sensors were } \\
\text { resolved after testing period. }\end{array}$ \\
\hline
\end{tabular}

\subsection{General Outcome of Laboratory Testing}

The Sympnia Smart Collector performs very well with a standard deviation of less than $6 \%$ in its measured data in steady state conditions. Further testing, that involves comparison of collected signals with those measured by a reference measuring device are crucial for the evaluation of the platform's measurement accuracy. Dedicated accuracy testing has been scheduled for the pilot testing period in the city of Thessaloniki, Greece and is part of the next testing steps, presented in Section Error! Reference source not found..

It is outlined that software testing followed a similar but firmly different procedure. The outcome of this procedure is not part of this work and will be included in our next efforts.

\section{Preliminary results}

Pilot testing involves 70 air quality, low-cost sensor devices embedded in 43 boards. The batch of the first 16 devices sent to Thessaloniki, Greece for the platform's pilot testing phase is presented in Fig. 19. Each board consists of either 1, 2 or 3 air quality sensors, covering every pollutant factor monitoring combination in various areas of the city. The sensors' spatial distribution was selected in such a way that, inter alia, a homogeneous distribution is achieved and areas with high expected levels of air pollution are covered.

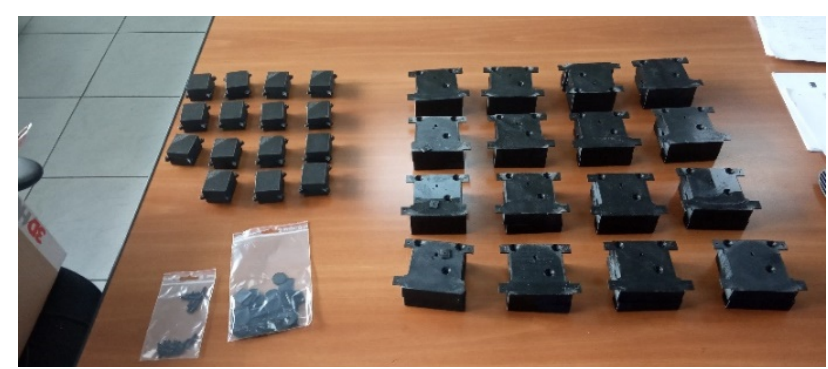

Fig. 19. The first 16 Sympnia Smart Collectors sent to Thessaloniki, Greece for pilot testing.

During this pilot testing phase, the Sympnia Smart Collectors' stability is going to be tested, since a number of devices are going to operate on a daily basis in different parts of the city of Thessaloniki. Moreover, a large number of data are going to be collected from all the installed devices, providing an adequate amount of data via which the system's accuracy is going to be tested. During this testing phase, a first air quality map of the city of Thessaloniki is going to be created, providing the citizens with useful health-related data for their neighborhood and city. The pilot testing period is 
currently ongoing, and the outcomes will be included in our next work. Fig. 20 presents indicative $\mathrm{PM}_{2.5}$ measurements from one collector for a period of 5 months. It is shown that the collector behaves according to what was expected without any issues keeping its stability and data integrity.

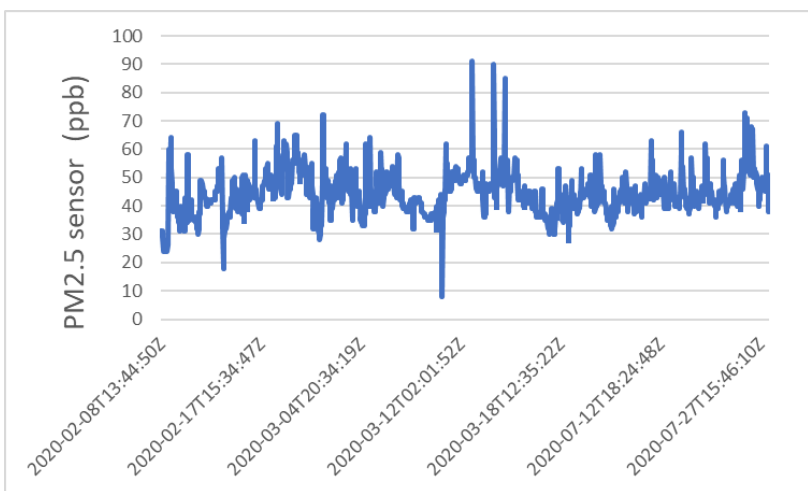

Fig. 20. PM2.5 measurements for a period of 5 months.

In addition, Fig. 21 presents the correlation between the data obtained by the $\mathrm{PM}_{2.5}$ and $\mathrm{PM}_{10}$ sensors from the same collector. As shown, the two sensors present a high level of linearity as was expected for the specific (urban environment) location. In a similar manner, Fig. 22 presents collected values from (up) $\mathrm{NO}_{2}$ and (down) $\mathrm{NO}$ sensors from the same collector for a period of 4 months. The satisfactory performance of the collectors in the field is confirmed in that occasion, too. The low values of the NO obtained in May 2020 that appear to be outliers and are further depicted in Fig. 23 as a secondary cluster of values, are currently under evaluation with cross-correlation based on ground station measurements.

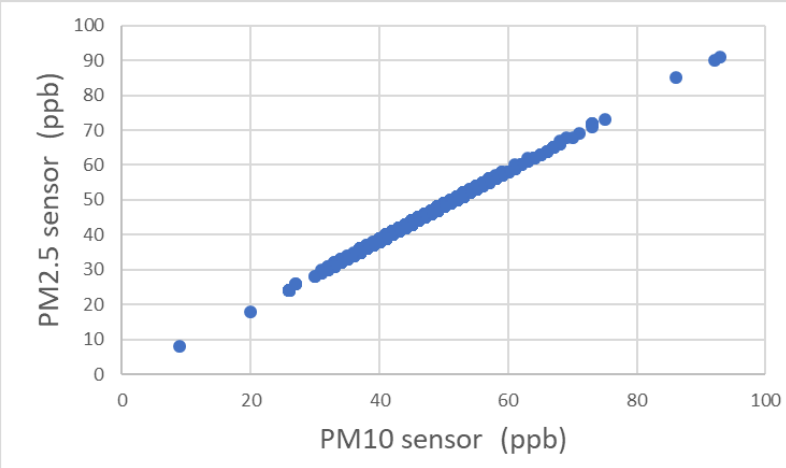

Fig. 21. Correlation of $\mathrm{PM}_{10}$ and $\mathrm{PM}_{2.5}$ measurements from the same collector for a period of 5 months.

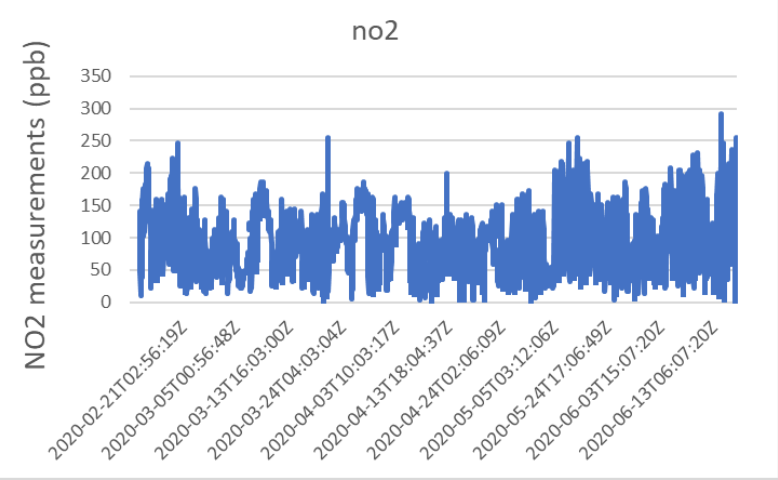

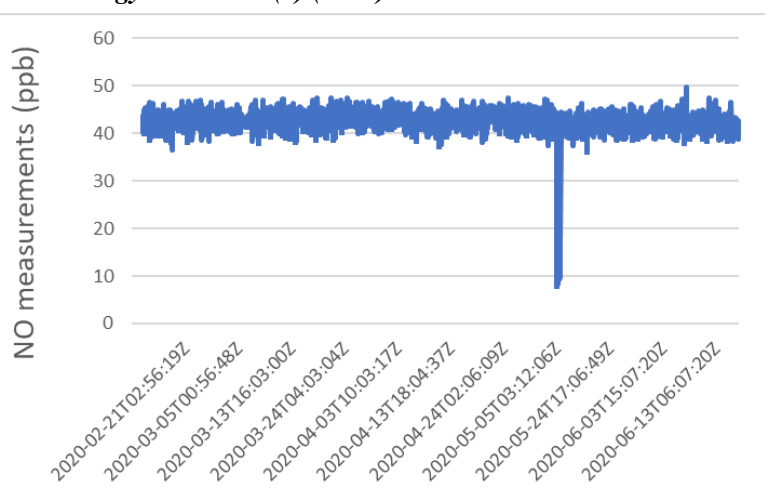

Fig. 22. (up) $\mathrm{NO}_{2}$ and (down) $\mathrm{NO}$ measurements from the same collector for a period of 5 months.

no2

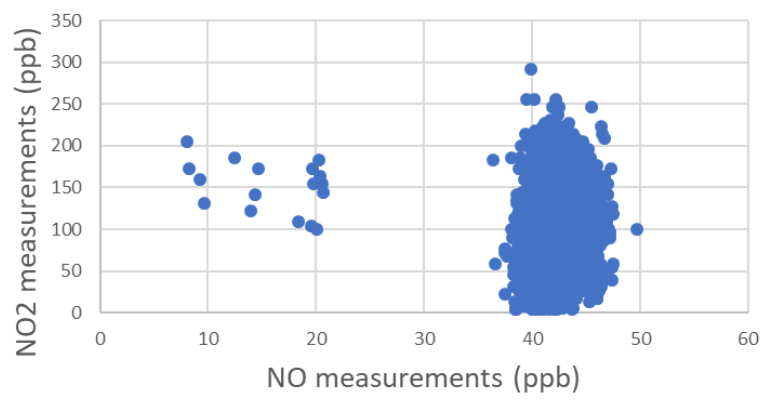

Fig. 23. Correlation of $\mathrm{NO}_{2}$ and $\mathrm{NO}$ measurements from the same collector for a period of 4 months.

Since part of the pilot testing occurred during the COVID19 lockdown in Greece, preliminary data regarding the air quality trends during the quarantine period in Greece (start day: $11 / 3 / 20$ end day: $4 / 5 / 20$ ) due to COVID-19 are presented.

Fig. 24 presents a trend analysis of $\mathrm{PM}_{10}$ measurements in two different regions of the city for the period before and right after the lockdown. The trending line shows decrease of emissions, but the rate of decrease is the expected for the season levels, taking also into account the temperature in the city. It must be noted that these collectors, while placed in the center of the city, they were installed in "protected" environments; that is, far from a main road and/or very close to a park.

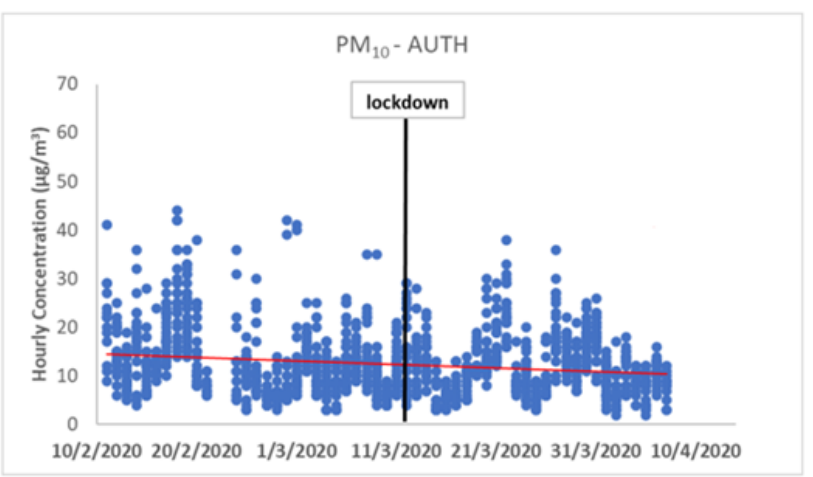




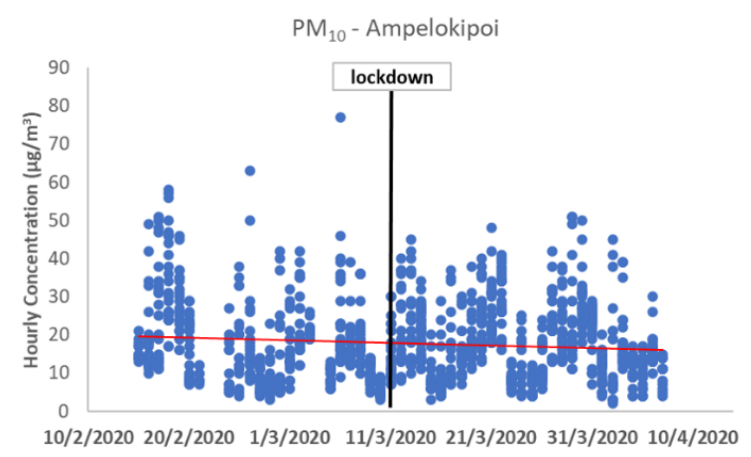

Fig. 24. $\mathrm{PM}_{10}$ measurements for two different regions in Thessaloniki. The time period includes the lockdown period due to COVID-19.

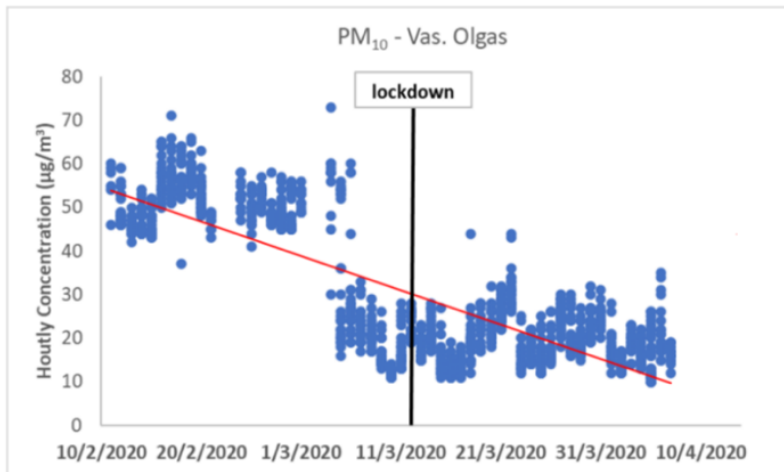

Fig. 25. $\mathrm{PM}_{10}$ measurements from Vas. Olgas region in Thessaloniki. The recorded time period includes the COVID-19 quarantine period.

Fig. 25 presents similar measurements from a third region that is very close to a major road of the city. It is observed that one week before the lockdown the emission levels were drastically reduced. The cause for this reduction could be the traffic reduction and mobility limitations within Thessaloniki due to the increase in COVID-19 incidents during that period. Going one step further, in Fig. 26 (a) and Fig. 26 (b), for this specific location in Thessaloniki the concentrations of both $\mathrm{PM}_{2.5}$ (a) and $\mathrm{O}_{3}$ (b) indicate a significant improvement of air quality during the reference period, while a hysteresis after the end of the lockdown is also depicted in the figures, as was expected. Of course, the results presented in this section are preliminary and further analysis would be needed before making any assumptions regarding the impact of the COVID19 pandemic on air quality, but they illustrate the ability of Sympnia Smart Collectors to provide support to the scientific community towards that direction.

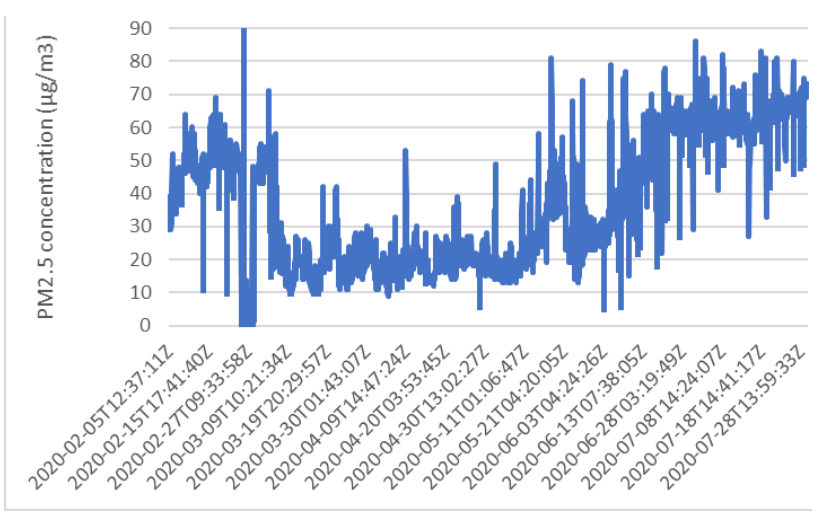

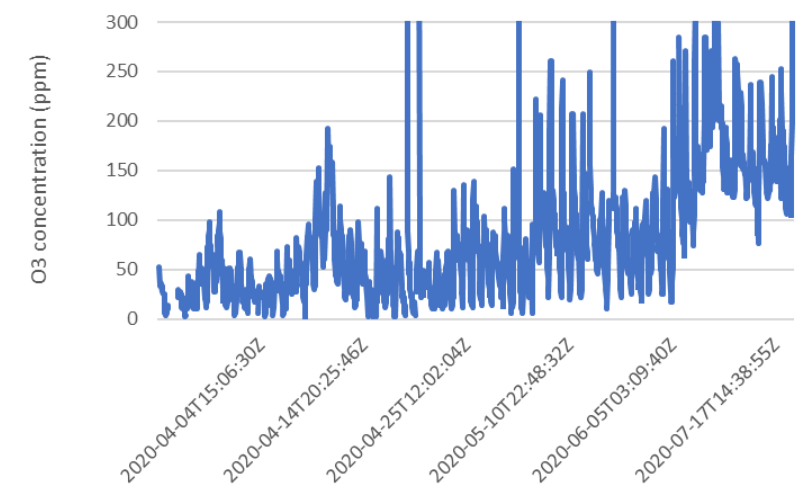

Fig. 26. $\mathrm{PM}_{10}$ (up) and $\mathrm{O}_{3}$ (down) measurements from Vas. Olgas region. The time period refers to the lockdown due to COVID-19.

\section{Conclusions}

In the present manuscript, a new and sustainable air quality sensor monitoring platform has been presented. The platform is able to operate with any combination of four types of sensors incorporated in a single Smart Collector. The Smart Collector acquires atmospheric measurements once per hour and transmits the data in JSON format via Wi-Fi to a remote server for further analysis. The designed platform is compact and low cost. In addition to that, it is able to operate using an 18650 Li-ion battery for five days and be charged using a USB 2.0 cable. The various laboratory tests and a preliminary analysis of the air quality data collected from various districts of the city of Thessaloniki showed that the Sympnia Smart Collector and the network created by a number of Smart Collectors spread throughout a city is a robust and reliable platform for monitoring air quality. Its uses could potentially range from public health monitoring to data analysis and scientific research.

Throughout this work, it was shown that the platform is able to provide a feasible, low cost, yet reliable solution for environmental monitoring IoT applications. It is envisioned that the platform will expand in order to house a larger selection of sensors. Future work will include the installation of a grid of 80 Smart Collectors in the city of Thessaloniki, Greece, along with the corresponding measurement and verification results.

\section{Acknowledgment}

This research has been co-financed by the European Union and Greek national funds through the Operational Program Competitiveness, Entrepreneurship and Innovation, under the call RESEARCH - CREATE - INNOVATE (project code: T1EDK-05515).

This is an Open Access article distributed under the terms of the Creative Commons Attribution License

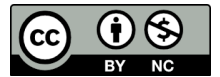




\section{References}

1. W. Y. Yi, K. M. Lo, T. Mak, K. S. Leung, Y. Leung, and M. L. Meng, "A survey of wireless sensor network based air pollution monitoring systems," Sensors (Switzerland), vol. 15, no. 12, pp. 31392-31427, 2015

2. W. Jiao et al., "Community Air Sensor Network (CAIRSENSE) project: Evaluation of low-cost sensor performance in a suburban environment in the southeastern United States," Atmos. Meas. Tech., vol. 9, no. 11, pp. 5281-5292, 2016.

3. S. Moltchanov, I. Levy, Y. Etzion, U. Lerner, D. M. Broday, and B. Fishbain, "On the feasibility of measuring urban air pollution by wireless distributed sensor networks," Sci. Total Environ., vol. 502, pp. 537-547, 2015.

4. W. Jiao, G. S. W. Hagler, R. W. Williams, R. N. Sharpe, L. Weinstock, and J. Rice, "Field assessment of the village green project: An autonomous community air quality monitoring system," Environ. Sci. Technol., vol. 49, no. 10, pp. 6085-6092, 2015.

5. G. R. McKercher, J. A. Salmond, and J. K. Vanos, "Characteristics and applications of small, portable gaseous air pollution monitors," Environ. Pollut., vol. 223, pp. 102-110, 2017.

6. L. Morawska et al., "Applications of low-cost sensing technologies for air quality monitoring and exposure assessment: How far have they gone?," Environ. Int., vol. 116, no. April, pp. 286-299, 2018.

7. E. G. Snyder et al., "The changing paradigm of air pollution monitoring," Environ. Sci. Technol., vol. 47, no. 20, pp. 11369$11377,2013$.

8. Honeywell, "HPM Series Particulate Matter Sensors.” p. 11, 2019.

9. Spec Sensors, "DGS-O3 968-042 Digital Gas Sensor - Ozone Sensor." 2020

10. Spec Sensors, "DGS-NO2 968-037 Digital Gas Sensor - Nitrogen Dioxide." 2020.
11. E.-G. S. L. Management, "0.02-4.8V CO, H2, H2S, No2 O2 sensor.” 2020.

12. Spandonidis C., Tsantilas S., Sedikos E., Galiatsatos N., Giannopoulos F., Papadopoulos P., Demagos N., Reppas D., Giordamlis C., "A Low-Cost Air Quality Monitoring Internet of Things Platform", International Journal of Urban and Civil Engineering, 14(11):382-388, 2020.

13. Spandonidis C., Giordamlis C., "Data-centric Operations in Oil \& Gas Industry by the Use of $5 \mathrm{G}$ Mobile Networks and Industrial Internet of Things (IIoT)," in Thirteenth International Conference on Digital Telecommunications (ICDT 2018), 2018, pp. 1-5, 2018.

14. Draxis Environmental S.A., "Envi4all." [Online]. Available: http://envi4all.eu/. [Accessed: 13-Sep-2020].

15. Espressif Systems, ESP8266 Technical Reference. 2020.

16. Espressif Systems, ESP32 Technical Reference Manual. 2020.

17. Themelis N., Spandonidis C., Giordamlis C., "Data acquisition and processing techniques for a novel performance monitoring system based on KPIs," in Sustainable Development and Innovations in Marine Technologies - Proceedings of the 18th International Congress of the International Maritime Association of the Mediterranean, IMAM 2019, pp. 306-31, 2019.

18. Spandonidis C., Tsantilas S., Sedikos E., Galiatsatos N., Giannopoulos F., Papadopoulos P., Demagos N., Reppas D., Giordamlis C., " A compact, modular and low-cost Internet of Things (IoT) platform for air quality montoring in urban areas", in Proceedings of the 2nd International Conference on Electronics Communication Technologies (ICECT2020)., J. Phys.: Conf. Ser. 1710 (2020) 012004, 2020. 